\title{
PENGARUH 1,4-BUTANDIOL SEBAGAI POLIOL PADA MODIFIKASI EPOKSI MENGGUNAKAN POLIURETAN
}

\author{
EFFECT OF 1,4-BUTANDIOL AS POLYOL \\ ON MODIFICATION OF EPOXY USING POLYURETHANE
}

\section{Muhammad Ghozali $^{1)}$, Agus Haryono ${ }^{1)}$, Asep Handaya Saputra ${ }^{2)}$ dan Evi Triwulandari $^{1)}$}

\author{
${ }^{1)}$ Pusat Penelitian Kimia - LIPI, Kawasan Puspiptek Serpong, 15314, Indonesia \\ ${ }^{2)}$ Fakultas Teknik Kimia, Universitas Indonesia, Kampus UI Depok, 16436, Indonesia \\ Email : ghoqun@yahoo.com
}

Diterima: 22 Januari 2015, Revisi: 17 Februari 2015, Disetujui: 27 Maret 2015

\begin{abstract}
ABSTRAK
Korosi merupakan fenomena alami yang menyebabkan penurunan nilai dan fungsi pada material. Penggunaan cat dan pelapis polimer merupakan metode yang paling umum untuk melindungi material dari korosi. Pelapis polimer yang digunakan merupakan resin organik berbasis epoksi dan poliuretan. Pada penelitian ini telah dilakukan modifikasi epoksi dengan poliuretan sehingga diperoleh bahan pelapis yang merupakan gabungan antara epoksi dan poliuretan. Diharapkan dengan adanya gabungan secara kimia antara bahan pelapis epoksi dan poliuretan tersebut dapat meningkatkan karakteristik bahan pelapis yang dihasilkan. Epoksi termodifikasi poliuretan dengan poliol 1,4-butandiol (ETP-BTD) dibuat dengan mereaksikan resin epoksi, tolonat dan poliol 1,4butandiol pada $50^{\circ} \mathrm{C}$ selama 30 menit dengan katalis dibutiltindilaurat. Analisis gugus fungsi ETP-BTD dilakukan dengan Fourier Transform Infra Red (FTIR), uji kuat tarik dilakukan dengan Ultimate Testing Machine (UTM), uji adhesi dengan ASTM D4541 Portable Pull-off Adhesion Testers, laju transmisi uap air dengan ASTM E96 Desiccant Method dan stabilitas termal dipelajari menggunakan Thermogravimetric Analysis (TGA). Hasil analisis FTIR menunjukkan adanya ikatan uretan pada bilangan gelombang 1716-1690 $\mathrm{cm}^{-1}$. Hasil penelitian menunjukkan bahwa modifikasi resin epoksi menggunakan poliuretan dapat meningkatkan nilai kuat tarik dan adhesi serta menurunkan laju transmisi uap air.
\end{abstract}

Kata kunci: epoksi, modifikasi, poliol, poliuretan; 1,4-butandiol

\footnotetext{
ABSTRACT

Corrosion is a natural phenomenon causing degradation value and function of material. The use
}

of paints and polymer coatings is the most popular method to protect material against corrosion. Polymer coatings used was an epoxy-based organic resin and polyurethane. Generally, those coating materials were used separately. This study carried out the modification of epoxy with polyurethane in order to obtain coating materials as a combination of epoxy and polyurethane. Expectedly, the chemical reaction between epoxy coating-material and polyurethane could improve the characteristics of the obtained coating materials. Synthesis of polyurethane-modified epoxy with 1,4-butanediol as the polyol (ETP-BTD) was conducted by reacting epoxy resin, tolonate and 1,4-butanediol simultaneously at $50{ }^{\circ} \mathrm{C}$ for $30 \mathrm{~min}$ with dibutyltindilaurate as catalyst. Functional group analysis of ETP-BTD was performed by Fourier Transform Infra Red (FTIR), tensile strength by Ultimate Testing Machine (UTM), adhesion by ASTM D4541 Portable Pull-off Adhesion Testers, water vapor transmission rate by ASTM E96 Desiccant Method and thermal stability was studied using Thermogravimetric Analysis (TGA). The FTIR analysis results showed that there are urethane bonds at 1716-1690 $\mathrm{cm}^{-1}$. These results showed that modification of epoxy using polyurethane increased the tensile strength and adhesion, and also decreased the water vapor transmission rate of epoxy.

Keywords: epoxy, modification, polyol, polyurethane, 1.4-butanediol

\section{PENDAHULUAN}

Korosi merupakan fenomena alami yang menyebabkan kerugian/penurunan nilai dan fungsi pada material melalui reaksi kimia atau elektrokimia antara logam 
dengan lingkungan. Korosi tidak dapat sepenuhnya dihindari atau dihilangkan tetapi dapat dicegah atau dikurangi dengan berbagai cara, antara lain menjaga kebersihan lingkungan, memadukan logam dengan logam lain yang lebih tahan terhadap korosi, menggunakan inhibitor yang berfungsi sebagai penghalang oksidasi, penggunaan cat dan pelapis. Diantara metode tersebut, penggunaan cat dan pelapis polimer merupakan metode yang paling umum digunakan karena biayanya murah dan mudah diaplikasikan. Cat dan pelapis polimer ini dapat memberikan perlindungan untuk jangka waktu tertentu sehingga dapat mencegah terjadinya korosi pada logam ${ }^{(1,2)}$.

Pada umumnya pelapis polimer yang digunakan untuk melindungi material dari korosi merupakan resin organik berbasis epoksi dan poliuretan yang memiliki keunikan sifat dan manfaat serta keterbatasan tertentu ${ }^{(3)}$. Resin berbasis epoksi umumnya digunakan sebagai resin matrik untuk pelapis polimer, adhesi dan komposit $^{(4)}$. Epoksi secara luas digunakan sebagai material pelindung untuk transportasi kelautan, konstruksi dibawah air, komponen pesawat luar angkasa dan komponen otomotif. Aplikasi untuk kebutuhan bidang-bidang tersebut memerlukan material pelapis yang memiliki stabilitas termal, ketahanan terhadap bahan kimia dan adhesi yang baik pada berbagai substrat $^{(5)}$.

Resin epoksi memiliki beberapa kelebihan antara lain merupakan adhesi yang baik pada berbagai permukaan, ringan, kekuatan yang baik, tahan lama, stabil terhadap uv dan tahan terhadap bahan kimia, tetapi resin epoksi juga memiliki beberapa kekurangan bila digunakan secara murni tanpa modifikasi atau campuran dengan bahan lain, yaitu getas sehingga mempengaruhi impact strength, kurang tahan lama, kurang tahan terhadap cuaca ${ }^{(3-}$ 6).
Resin organik lain yang biasa dipakai sebagai material pelapis yaitu poliuretan karena memiliki beberapa kelebihan, antara lain dalam hal penampakan dan tahan lama, ketahanan terhadap cuaca, tetapi poliuretan juga peka terhadap kelembaban. Poliuretan merupakan polimer yang terdiri atas rantai organik yang tergabung dengan rantai uretan. Poliuretan terbentuk melalui polimerisasi step-growth. Rantai uretan RNHCOOR' dihasilkan melalui reaksi antara gugus isosianat $(\mathrm{N}=\mathrm{C}=\mathrm{O})$ dengan gugus hidroksil $(\mathrm{OH})$. Poliol berpengaruh terhadap sifat poliuretan, sedangkan isosianat berpengaruh pada kecepatan pengeringan. Rasio molar antara gugus hidroksil dan gugus isosianat yang tepat dapat menghasilkan sifat pelapis yang optimal $^{(7)}$.

Berkaitan dengan keunggulan sifat yang dimilikinya, poliuretan dapat digunakan untuk meningkatkan sifat resin epoksi. Modifikasi kimia merupakan salah satu metode untuk mengatasi kelemahan dan meningkatkan sifat epoksi. Salah satu modifikasi yang dapat dilakukan adalah proses pencangkokan. Penelitian tentang pencangkokan resin epoksi-poliuretan untuk mengatasi kelemahan epoksi yang menyangkut kerapuhan/kegetasan epoksi serta meningkatkan sifat elastis, sifat adhesi, sifat mekanik, stabilitas termal, dan ketahanan kimia telah dilakukan ${ }^{(4-8)}$.

Modifikasi kimia menggunakan poliuretan pada umumnya dilakukan dengan pembuatan prepolimer poliuretan terlebih dahulu. Metode ini memiliki kelemahan karena poliuretan yang terbentuk biasanya mudah mengeras ${ }^{(9)}$. Penelitian ini bertujuan membuat material pelapis epoksi termodifikasi poliuretan dengan poliol 1,4-butandiol (ETP-BTD) tanpa melalui pembuatan prepolimer terlebih dahulu. 


\section{BAHAN DAN METODE}

\section{Bahan}

Bahan kimia yang digunakan adalah resin epoksi bisfenol A (epoksi YD 128), tolonat (sebagai isosianat) dan hardener / curing agent (Versamide 140) yang diperoleh dari PT. Sigma Utama, dan 1,4butandiol diperoleh dari E-Merck.

Epoksi termodifikasi poliuretan dengan poliol 1,4-butandiol (ETP-BTD) dibuat dengan cara mereaksikan secara bersama-sama antara epoksi, tolonat (sebagai isosianat) dan 1,4-butandiol (sebagai poliol) dalam labu leher tiga pada $50^{\circ} \mathrm{C}$ selama 30 menit dengan kecepatan pengadukan sekitar $200 \mathrm{rpm}$ dengan katalis dibutiltindilaurat (DBTL) $0,1 \%$ (berat/berat). Rasio molar $\mathrm{NCO} / \mathrm{OH}$ antara isosianat dengan poliol 1,4-butandiol yaitu 0,5 dan 2,5. Komposisi epoksi termodifikasi poliuretan dengan poliol 1,4butandiol (ETP-BTD) dengan variasi rasio molar $\mathrm{NCO} / \mathrm{OH}$ 0,5 dan 2,5 dan variasi penambahan poliuretan sebesar $5-20 \%$ (berat/berat) dapat dilihat pada Tabel 1 .

Tabel 1. Komposisi ETP-BTD

\begin{tabular}{|c|c|c|}
\hline \multirow{2}{*}{$\begin{array}{c}\text { Poliuretan } \\
\text { dalam } \\
\text { Epoksi } \\
\text { (\% berat) }\end{array}$} & \multicolumn{2}{|c|}{$\begin{array}{l}\text { 1,4-Butandiol } \\
\text { (BTD) }\end{array}$} \\
\hline & $\begin{array}{c}\text { Rasio } \mathrm{NCO} / \mathrm{OH}= \\
0,5\end{array}$ & $\begin{array}{c}\text { Rasio } \mathrm{NCO} / \mathrm{OH}= \\
2,5\end{array}$ \\
\hline 5 & ETP-BTD 0,5R 5E & ETP-BTD 2,5R 5E \\
\hline 10 & ETP-BTD $0,5 \mathrm{R} 10 \mathrm{E}$ & ETP-BTD 2,5R 10E \\
\hline 15 & ETP-BTD $0,5 \mathrm{R} 15 \mathrm{E}$ & ETP-BTD 2,5R 15E \\
\hline 20 & ETP-BTD $0,5 \mathrm{R} 20 \mathrm{E}$ & ETP-BTD 2,5R 20E \\
\hline
\end{tabular}

Film epoksi termodifikasi poliuretan dibuat dengan menambahkan curing agent (hardener) dengan perbandingan berat antara epoksi termodifikasi poliuretan dengan curing agent yaitu 2:1. Pembuatan film dilakukan di atas permukaan papan polietilen dengan ketebalan film 0,3 mm. Film yang dihasilkan kemudian dianalisis uji kuat tarik, uji laju transmisi uap air serta dan uji sifat termal. Uji adhesi film epoksi termodifikasi poliuretan dilakukan diatas plat besi.

Analisis Fourier Transform Infrared (FTIR) dilakukan dengan instrumen IR Prestige-21 Shimadzu untuk mempelajari adanya perubahan gugus fungsi dengan cara membandingkan spektrum epoksi dengan epoksi termodifikasi poliuretan dengan poliol 1,4-butandiol (ETP-BTD). Stabilitas termal epoksi termodifikasi poliuretan dengan poliol 1,4-butandiol (ETP-BTD) dipelajari dengan instrumen Thermogravimetric Analysis Setaram Lab Sys Evo.

Uji kuat tarik resin epoksi dan produk epoksi termodifikasi poliuretan dengan poliol 1,4-butandiol (ETP-BTD) dilakukan pada suhu kamar dengan kelembaban relatif 40-60\% menggunakan alat Ultimate Testing Machine (UTM). Film epoksi termodifikasi poliuretan (ETP) berukuran $10 \mathrm{~cm} \mathrm{x} \mathrm{2,54}$ $\mathrm{cm}$ dengan ketebalan sekitar 0,3 $\mathrm{mm}$ dipasang di antara pegangan (grip) instrument uji kuat tarik. Kekuatan tarik diukur sebagai kekuatan maksimum pada saat sampel putus dibagi dengan luas penampang sampel.

Epoksi dan epoksi termodifikasi poliuretan dengan poliol 1,4-butandiol (ETP-BTD) diuji daya lekatnya (adhesi) menggunakan metode pull-off test ASTM D4541. Dolly pin dilekatkan pada lembaran besi yang sudah dilapisi dengan material pelapis yaitu epoksi dan epoksi termodifikasi poliuretan dengan poliol 1,4butandiol (ETP-BTD) dengan ketebalan 0,3 $\mathrm{mm}$. Dolly pin kemudian ditarik ke atas hingga lapisan material pelapis terlepas dari lembaran besi.

Pengujian laju transmisi uap air pada epoksi dan epoksi termodifikasi poliuretan dengan poliol 1,4-butandiol (ETP-BTD) dilakukan menggunakan ASTM E96 Desiccant Method pada $37,8^{\mathrm{O}} \mathrm{C}$ dengan kelembaban relatif 90\%. Sampel dengan ketebalan $0,3 \mathrm{~mm}$ dan diameter $10-15 \mathrm{~cm}$ diletakkan pada open mouth test dish yang 
didalamnya mengandung absorber. Udara dengan kecepatan 0,02-0,3 m/detik dialirkan melewati spesimen sampel. Absorber kemudian ditimbang secara berkala untuk menentukan kecepatan laju transmisi uap air.

\section{HASIL DAN PEMBAHASAN}

Spektrum FTIR epoksi termodifikasi poliuretan dengan poliol polipropilen glikol ditunjukkan (ETP-PPG) pada Gambar 1.

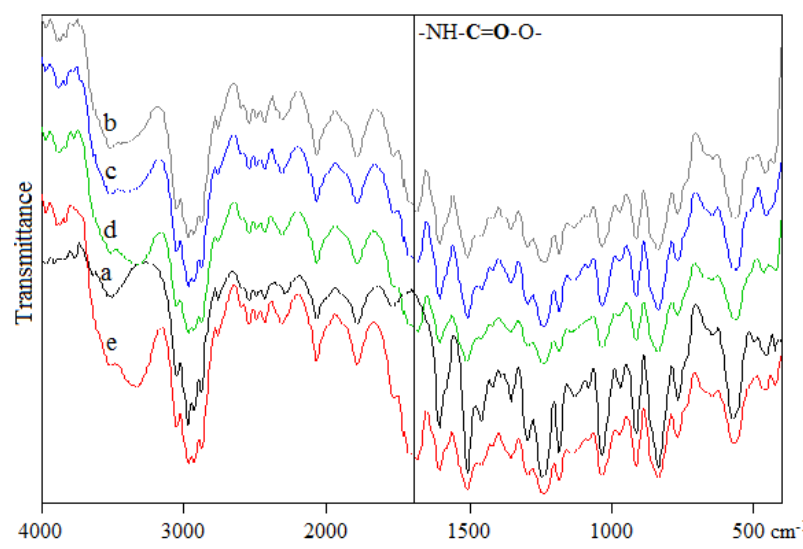

Gambar 1. Spektum FTIR: a) Epoksi; b) ETP-BTD 5E; c) ETP- BTD 10E; d) ETP- BTD $15 \mathrm{E}$ dan e) ETP- BTD 20E

Spektrum FTIR resin epoksi (Gambar 1a) menunjukkan adanya puncak serapan pada bilangan gelombang $3550-3450 \mathrm{~cm}^{-1}$ yang menunjukkan gugus hidroksil $(\mathrm{OH})$ dari resin epoksi ${ }^{(9,10)}$.

Pada epoksi termodifikasi poliuretan dengan poliol 1,4-butandiol (ETP-BTD) (Gambar 1b-e) muncul puncak serapan pada bilangan gelombang $3500-3270 \mathrm{~cm}^{-1}$ yang juga menunjukkan adanya gugus hidroksil $(\mathrm{OH})$ tetapi bukan gugus hidroksil $(\mathrm{OH})$ yang berasal resin epoksi melainkan gugus hidroksil $(\mathrm{OH})$ yang berasal dari poliol 1,4-buatandiol, pergeseran puncak serapan ini dipengaruhi oleh adanya gugus $\mathrm{NH}{ }^{(11)}$. Epoksi termodifikasi poliuretan dengan poliol 1,4-butandiol (ETP-BTD) juga menunjukkan adanya puncak serapan baru pada bilangan gelombang 1716-1690 $\mathrm{cm}^{-1}$ yang menunjukkan gugus $\mathrm{COO}$ yang berasal dari ikatan uretan $-\mathrm{NH}-\mathrm{C}=\mathrm{O}-\mathrm{O}-$. Hal ini mengindikasikan bahwa telah terjadi reaksi antara gugus hidroksil $(\mathrm{OH})$ yang berasal dari resin epoksi dan poliol 1,4butandiol dengan gugus isosianat $(\mathrm{N}=\mathrm{C}=\mathrm{O})$ yang berasal dari tolonat sehingga membentuk ikatan uretan $-\mathrm{NH}-\mathrm{C}=\mathrm{O}-\mathrm{O}-$ $(9,12)$

Mekanisme kimia pembentukan epoksi termodifikasi poliuretan dengan poliol 1,4-butandiol (ETP-BTD) ditunjukkan pada Gambar 2.

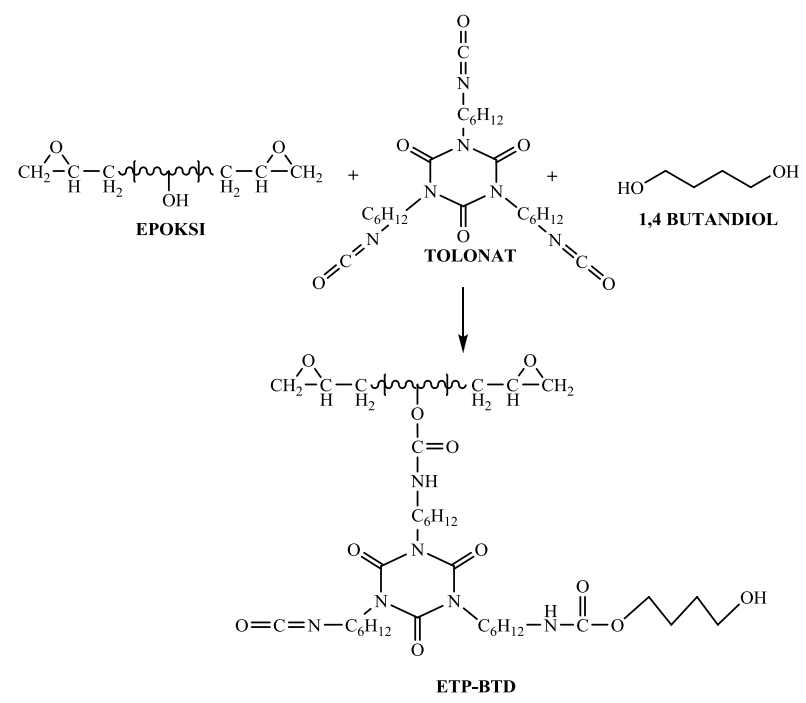

Gambar 2. Struktur Kimia ETP-BTD

Tabel 2. Kuat Tarik ETP-BTD

\begin{tabular}{ccc}
\hline $\begin{array}{c}\text { Poliuretan } \\
\text { dalam }\end{array}$ & \multicolumn{2}{c}{$\begin{array}{c}\text { Kuat Tarik ETP-BTD } \\
\left(\mathbf{k g f} / \mathbf{c m}^{2}\right)\end{array}$} \\
\cline { 2 - 3 } $\begin{array}{c}\text { Epoksi } \\
\text { \% berat) }\end{array}$ & $\begin{array}{c}\text { Rasio NCO/OH }= \\
\mathbf{0 , 5}\end{array}$ & $\begin{array}{c}\text { Rasio NCO/OH }= \\
\mathbf{2 , 5}\end{array}$ \\
\hline 0 & & 69,61 \\
5 & 136,34 & \\
10 & 127,93 & 93,16 \\
15 & 118,17 & 89,07 \\
20 & 103,09 & 88,18 \\
\hline
\end{tabular}

Pada produk epoksi termodifikasi poliuretan dengan poliol 1,4-butandiol (ETP-BTD) menunjukkan bahwa peningkatan rasio $\mathrm{NCO} / \mathrm{OH}$ dan peningkatan komposisi poliuretan dalam epoksi termodifikasi poliuretan dengan poliol 1,4-butandiol (ETP-BTD) akan menurunkan nilai kekuatan tarik. 
Peningkatan nilai kuat tarik ini dipengaruhi oleh adanya poliuretan yang mengandung soft segment dan hard segment dalam struktur ETP-BTD. Ketika ETP-BTD dikenakan gaya maka bagian soft segment dan hard segment yang ada pada poliuretan akan berorientasi sehingga mempengaruhi ikatan hidrogen yang dapat meningkatkan nilai kuat tarik ETP-BTD ${ }^{(13-16)}$. Hal ini membuktikan bahwa modifikasi epoksi dengan poliuretan dapat meningkatkan nilai kuat tarik epoksi. Makin banyak poliuretan yang ditambahkan pada komposisi ETPBTD dapat menyebabkan penurunan nilai kuat tarik. Hal ini disebabkan oleh karena semakin banyak poliuretan yang ditambahkan ke dalam ETP-BTD akan menyebabkan ETP-BTD semakin fleksibel dan elastis. Sifat fleksibel dan elastis ini disebabkan oleh hadirnya 1,4-butandiol, karena ketika poliol linear bifunctional yang digunakan untuk membuat rantai uretan maka sifat poliuretan tersebut akan menjadi lebih fleksibel dan elastis sehingga hanya membutuhkan sedikit gaya untuk memutuskan atau merusak ETP-BTD ${ }^{(12)}$.

Tabel 3. Nilai Adhesi ETP-BTD

\begin{tabular}{ccc}
\hline $\begin{array}{c}\text { Poliuretan } \\
\text { Dalam }\end{array}$ & \multicolumn{2}{c}{$\begin{array}{c}\text { Nilai Adhesi ETP-BTD } \\
\text { ( MPa })\end{array}$} \\
\cline { 2 - 3 } $\begin{array}{c}\text { Epoksi } \\
\text { \% berat) }\end{array}$ & $\begin{array}{c}\text { Rasio NCO/OH }= \\
\mathbf{0 , 5}\end{array}$ & $\begin{array}{c}\text { Rasio NCO/OH }= \\
\mathbf{2 , 5}\end{array}$ \\
\hline 0 & & 3,8 \\
5 & 2,9 & 2,0 \\
10 & 3,8 & 4,7 \\
15 & 1,8 & 2,6 \\
20 & 6,0 & 6,0 \\
\hline
\end{tabular}

Penambahan komposisi poliuretan ke dalam resin epoksi dapat meningkatkan nilai adhesi produk epoksi termodifikasi poliuretan dengan poliol 1,4-butandiol (ETP-BTD). Hal ini disebabkan oleh adanya ikatan hidrogen dalam epoksi termodifikasi poliuretan dengan poliol 1,4butandiol (ETP-BTD). Ketika pelapis polimer diaplikasikan pada substrat, reaksi kimia akan terjadi antara dua permukaan, yaitu substrat dengan pelapis melalui interaksi gugus fungsi polar, jembatan hidrogen atau interaksi kimia antara pelapis dengan substrat ${ }^{(17)}$.

Tabel 4. Laju Transmisi Uap Air ETP-BTD

\begin{tabular}{ccc}
\hline $\begin{array}{c}\text { Poliuretan } \\
\text { dalam }\end{array}$ & \multicolumn{2}{c}{$\begin{array}{c}\text { Laju Transmisi Uap Air ETP-BTD } \\
\left(\mathbf{g} /\left(\mathbf{m}^{2} . \text { hari }\right)\right)\end{array}$} \\
\cline { 2 - 3 } $\begin{array}{c}\text { Epoksi } \\
\text { \% berat })\end{array}$ & $\begin{array}{c}\text { Rasio NCO/OH }= \\
\text { Rasio NCO/OH }= \\
\mathbf{0 , 5}\end{array}$ \\
\hline 0 & & 10,45 \\
15 & 4,07 & 2,39 \\
10 & 4,71 & 3,96 \\
15 & 6,47 & 8,22 \\
20 & 2,90 & 3,85 \\
\hline
\end{tabular}

Epoksi termodifikasi poliuretan dengan poliol 1,4-butandiol memiliki nilai laju transmisi uap air yang lebih rendah daripada resin epoksi. Hal ini kemungkinan disebabkan karena semakin menurunnya sifat penyerap air dan semakin meningkatkan sifat hidropobik epoksi termodifikasi poliuretan dengan poliol 1,4butandiol (ETP-BTD). Semua epoksi termodifikasi poliuretan dengan poliol 1,4butandiol (ETP-BTD) menunjukkan penurunan terhadap penyerapan kelembaban yang disebabkan oleh struktur rigid aromatic hidrophobik. Hal ini menunjukkan bahwa penggunaan poliol 1,4-butandiol dalam dalam ETP-BTD akan meningkatkan ketahanan penyerapan kelembaban dalam epoksi termodifikasi poliuretan dengan poliol 1,4-butandiol (ETP-BTD).

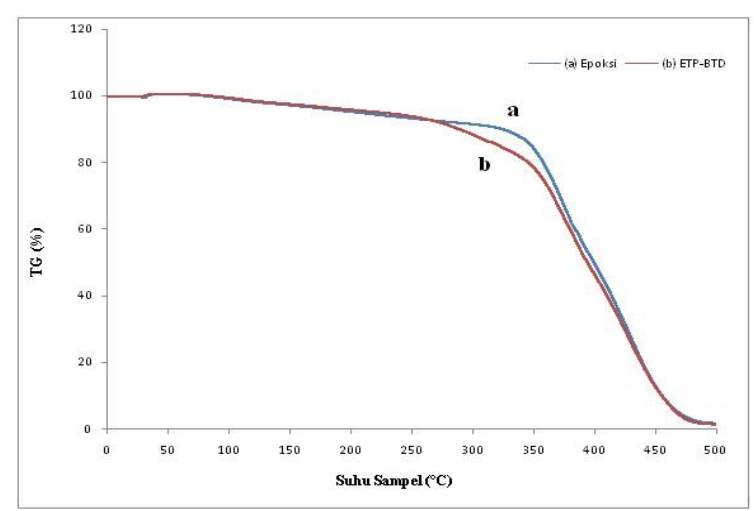

Gambar 3. Spektrum TGA a) Epoksi dan b) ETPBTD 
Stabilitas termal resin epoksi dan epoksi termodifikasi poliuretan dengan poliol 1,4-butandiol (ETP-BTD) ditunjukkan pada gambar 3. Stabilitas termal epoksi dan epoksi termodifikasi poliuretan dengan poliol 1,4-butandiol (ETP-BTD) menunjukkan kemiripan kecenderungan penurunan massa pada suhu 0-265 ${ }^{\circ} \mathrm{C}$. Akan tetapi pada suhu diatas 265-425 ${ }^{\circ} \mathrm{C}$ penurunan massa epoksi termodifikasi poliuretan dengan poliol 1,4butandiol (ETP-BTD) lebih cepat daripada resin epoksi. Hal ini disebabkan oleh adanya ikatan uretan yang rentan terhadap panas yang berasal dari reaksi antara 1,4butandiol dengan tolonat sehingga menyebabkan terjadinya penurunan stabilitas termal epoksi termodifikasi poliuretan dengan poliol 1,4-butandiol (ETP-BTD) sehingga laju penurunan massa epoksi termodifikasi poliuretan dengan poliol 1,4-butandiol (ETP-BTD) lebih cepat daripada epoksi ${ }^{(18)}$.

\section{KESIMPULAN}

Epoksi termodifikasi poliuretan dengan poliol 1,4-butandiol (ETP-BTD) telah disintesis tanpa melalui tahap poliuretan dengan cara mereaksikan epoksi, tolonat dan poliol 1,4-butandiol secara bersamaan. Hasil analisis FTIR membuktikan bahwa telah terjadi reaksi antara epoksi, tolonat dan 1,4-butandiol dengan terbentuknya ikatan uretan pada epoksi termodifikasi poliuretan dengan poliol 1,4-butandiol (ETP-BTD). Modifikasi epoksi menggunakan poliuretan dengan poliol 1,4-butandiol dapat meningkatkan nilai kuat tarik dan adhesi serta menurunkan laju transmisi uap air resin epoksi pada komposisi tertentu.

\section{UCAPAN TERIMAKASIH}

Penulis mengucapkan terima kasih kepada Program Kompetitif LIPI 2014 dan
Kementrian Riset dan Teknologi atas dukungan finansial yang telah diberikan. Penulis juga mengucapkan terima kasih kepada PT. Sigma Utama yang telah membantu menyediakan bahan baku.

\section{DAFTAR PUSTAKA}

1. S. Ahmad, F. Zafar, E. Sharmin, N. Garg and M. Kashif. Synthesis and characterization of corrosion protective olyurethanefattyamide/silica hybrid coating material. Progress in Organic Coatings. 73:112-117 (2012)

2. V.H.V Sarmento, M.G. Schiavetto, P. Hammer, A.V. Benedetti, C.S. Fugivara, P.H. Suegama, S.H. Pulcinelli and C.V. Santilli. Corrosion protection of stainless steel by polysiloxane hybrid coatings prepared using the sol-gel process. Surface \& Coatings Technology. 204:2689-2701. (2010)

3. J.M. Keijman, Properties and use of inorganic polysiloxane hybrid coating for the protective coatings industry. At: $2^{\text {as }}$ Jornadas Da Revista Corrosão E Protecção de Materiais Lisboa, 2000.

4. S. Lu, J. Ban, C. Yu, and W. Deng. Properties of Epoxy Resins Modified with Liquid Crystalline Polyurethane. Iranian Polymer Journal. 19(9):6696780 (2010)

5. T. Li, M.J. Heinzer1, E.M. Redline, F. Zuo, F.S. Bates and L.F. Francis. Microstructure and performance of block copolymer modified epoxy coatings. Progress in Organic Coatings. 77:1145-1154 (2014)

6. K. Dinakaran, M. Alagar and R.S. Kumar. Preparation and characterization of bismaleimide/1,3-dicyanatobenzene modified epoxy intercrosslinked matrices. European Polymer Journal. 39:2225-2233. (2003)

7. E.A. Papaj, D.J. Mills and S.S. Jamali. Effect of hardener variation on 
protective properties of polyurethane coating. Progress in Organic Coatings. 77:2086-2090 (2014)

8. S. Chen, Y. Tian, L. Chen and T. Hu. Epoxy resin/polyurethane hybrid networks synthesized by frontal polymerization. Chemical Materials. 18(8):2159-2163 (2006).

9. K. Bouchemal, S.E. Perrier, H. Fessi, I. Bonnet and N. Zydowicz. Synthesis and characterization of polyurethane and poly (ether urethane) a nocapsules using a new technique of interfacial polycondensation combined to spontaneous emulsification. International Journal of Pharmaceutics. 269:89-100 (2004)

10. M. Bagheri, and R.Z. Rad. Synthesis and Characterization of main Chain Liquid Crystalline Polyesters Containing 2,5-bis (4exyloxybenzoyloxy) hydroquinone and terephthalate Unit. Iran Polymer Journal. 15:477-486. (2006)

11. Christenson, C.P., M.A. Harthcock and M.D. Meadows. Model MDI/Butanediol Morphology, Physical and Mechanical Properties. Journal Polymer Sciences. Polymer Physics. 24:1401-1409 (1986)

12. Hsieh, K.H. and J.L. Han. Graft interpenetrating polymer networks of polyurethane and epoxy. I. Mechanical behavior. Journal Polymer Sciences., Part B, Polymer Physics. 28(5)623-630 (1990)

13. G. Oertel, Polyurethane handbook. 2nd ed. Munich:Carl Hanser Verlag, 1994.

14. D. Randall, dan S.Lee. The polyurethanes book. New York: John Wiley \& Sons, 2003.

15. J. Blackwell, M.R. Nagarajan dan T.B. Hoitink. The structure of the hard segments in MDI/diol/PTMA polyurethane elastomers. In Edwars, K.E. Urethane Chemistry and Applications. Washington D.C.
American Chemical Society. 171:179196 (1981)

16. J. Blackwell, and K.H. Gardner. Structure of the hard segments in polyurethane elastomers. Polymer. 20(1)13-17 (1979)

17. M.A. Butt, A. Chughtai, J. Ahmad, R. Ahmad, U. Majeed and I.H. Khan. Journal of Faculty of Engineering and Technology. 21-45 (2008)

18. Prabu, A.A. and M. Alagar. Mechanical and thermal studies of intercross-linked network based on siliconized polyurethane-epoxy/unsaturated polyester coating. Progress in Organic Coatings. 49:236-243 (2004) 
JKTI, Vol. 17, No. 1, Juni 2015 